ОСНОВНЫЕ НАПРАВЛЕНИЯ СОВЕРШЕНСТВОВАНИЯ АДМИНИСТРАТИВНОПРАВОВОГО СТАТУСА УПОЛНОМОЧЕННОГО ЭКОНОМИЧЕСКОГО ОПЕРАТОРА

\author{
А.Д. ГАЛОЯН, Е.В. ЧЕКУШКИН, К.В. ТРУБИЦЫН, В.К. ТКАЧЕВ \\ ФГБОУ ВО «Самарский государственный технический университет», г. Самара
}

В статье проанализированы основные направления совершенствования административно-правового статуса уполномоченного экономического оператора, как на территории Российской Федерации, так и в других странах - участницах Евразийского экономического союза. Показано место института уполномоченного экономического оператора в Стратегии развития таможенной службы РФ до 2020 года. Представлено понятие УЭО в таможенном законодательстве ЕАЭС с учетом принятия Рамочных стандартов безопасности упрощения мировой торговли. В части разрешения вопросов, связанных с реализацией потенциальных возможностей для УЭО, исследовано таможенное законодательство ЕАЭС, особенности правоприменительной практики таможенных органов государств-членов ЕАЭС, а также практика таможенного администрирования за рубежом. Выявлены проблемные вопросы в части отсутствия необходимого понятийного аппарата при возможной разработке концепции совершенствования административно-правового статуса УЭО. В результате исследования правоприменительной практики выявлены отдельные проблемные аспекты института уполномоченного экономического оператора. В peзультате оценки современной практики таможенного администрирования сформулированы основные направления совершенствования административно-правового статуса УЭО в ЕАЭС на современном этапе.

Ключевые слова: уполномоченный экономический оператор; Стратегия развития таможенной службы РФ до 2020 года; Евразийский экономический союз; Рамочные стандарты безопасности упрощения мировой торговли; унификация специальных упрощений; таможенное администрирование.

Введение института уполномоченного экономического оператора (УЭО) в российскую таможенную практику является важным этапом в развитии системы взаимодействия таможенной службы и участников ВЭД.

В соответствии со Стратегией развития таможенной службы РФ до 2020 года введение института УЭО поставлено в один ряд с такими значительными шагами на пути либерализации и упрощения таможенных процедур, как расширение практики электронного декларирования, внедрение технологии удаленного выпуска, внедрение практики обязательного предварительного информирования о ввозимых товарах, сокращение срока выпуска товаров высокой степени переработки, определение минимального перечня документов, необходимых для представления в таможенных целях, введение института уполномоченного экономического оператора, обеспечение возможности выпуска товаров до подачи таможенной деклара- ции, применение новых технологий уплаты таможенных платежей. ${ }^{1}$

Как известно, институт УЭО был введен в таможенное законодательство Таможенного союза Республики Беларусь, Республики Казахстан и Российской Федерации (ТС) с учетом принятия Рамочных стандартов безопасности упрощения мировой торговли (Рамочные стандарты), разработанных в условиях тесного сотрудничества государств-членов Всемирной таможенной организации (ВТамО). Рамочные стандарты включают концепцию уполномоченного экономического оператора и определяют основные положения института, являясь техническим руководством по применению программ УЭО между государствами-членами ВТамО и торговым сообществом. Стандарты являются основой для разработки таможенными адми-

\footnotetext{
${ }^{1}$ Распоряжение Правительства РФ от 28.12.2012 № 2575-р «Об утверждении Стратегии развития таможенной службы Российской Федерации до 2020 года» // Собрание законодательства Российской Федерации. - 14.01.2013.- №2.- Ст. 109.
} 
нистрациями национальных программ уполномоченного экономического оператора.

Согласно Рамочным стандартам уполномоченный экономический оператор - это субъект, вовлеченный в международную торговлю товарами, чья деятельность получила одобрение таможенной администрации как соответствующая нормам ВТамО или стандартам обеспечения безопасной цепи поставки товаров. ${ }^{2}$ Отмечено также, что уполномоченными экономическими операторами могут быть импортеры и экспортеры.

Исследование таможенного законодательства Евразийского экономического союза (ЕАЭС), особенностей правоприменительной практики таможенных органов государствчленов ЕАЭС, а также практики таможенного администрирования за рубежом показало, что на теоретическом и на практическом уровне остается комплекс неразрешенных вопросов в связи с реализацией потенциальных возможностей для УЭО.

Если задаться вопросом о возможной разработке некой концепции совершенствования административно-правового статуса УЭО, а также расширении специальных упрощений, предоставляемых УЭО, приходится констатировать отсутствие необходимого понятийного аппарата. Проблематично совершенствовать правовой статус УЭО или расширять специальные упрощения, категорировать УЭО, если ни теория таможенного права, ни действующее законодательство ЕАЭС не раскрывают эти понятия. Причем ответ на этот вопрос не содержится ни в Рамочных стандартах, ни в аналитических материалах по передовой правоприменительной практике УЭО. Казалось бы, выявленные проблемные вопросы института УЭО должны отсылать к соответствующим национальным программам, планам по совершенствованию административно-правового статуса УЭО в государствах-членах ЕАЭС. Такие документы, безусловно, существуют. Однако их содержание применительно к институту УЭО требует уточнения.

Например, Распоряжением Правительства РФ от 29.06.2012 № 1125-р утвержден план мероприятий «Совершенствование таможенного администрирования», где для уполно-

\footnotetext{
2 Международная конвенция об упрощении и гармонизации таможенных процедур (Совершено в Киото 18 мая 1973 г., в ред. Протокола от 26 июня 1999 г.).
}

моченного экономического оператора российская сторона обозначила 2 перспективы:

1. Унификация специальных упрощений для уполномоченных экономических операторов производственного или иного типа, при условии, что такая унификация не приводит к сокращению их преимуществ, льгот и привилегий. При этом ожидаемый результат упрощения, установленные для УЭО производственного типа, установлены для всех типов УЭО.

2. Осуществление выпуска товаров до подачи декларации на товары без расчета сумм обеспечения по конкретной товарной партии для всех УЭО. Ожидаемый результат - обеспечен выпуск товаров, декларируемых уполномоченным экономическим оператором, без расчета сумм обеспечения уплаты таможенных платежей по конкретной товарной партии. ${ }^{3}$

На сегодняшний день в таможенном законодательстве ЕАЭС и таможенном законодательстве государств-членов ЕАЭС имеет место некоторый диссонанс в части определения отдельных терминов института УЭО. Более того, наряду с общепринятыми терминами (например, «унификация (в праве)») законодатель использует такие термины, как «унификация специальных упрощений», «УЭО производственного типа», «УЭО иного типа», «режим транспортно-логистических компаний», «переход УЭО по товарам народного потребления на режим».

Например, если в таможенном законодательстве и теории права отсутствует определение термина «специальные упрощения», то не ясно, что следует понимать под термином «унификация специальных упрощений».

Так, под унификацией понимают установление оптимального числа размеров или видов продукции, процессов или услуг, необходимых для удовлетворения основных потребностей $^{4}$, а под унификацией в праве деятельность компетентных органов государства или нескольких государств, направленная на выработку правовых норм, единооб-

\footnotetext{
3 Пункты 67-68 Распоряжения Правительства РФ от 29.06.2012 г. № 1125-р «Об утверждении плана мероприятий(«дорожной карты») «Совершенствование таможенного администрирования» [Электронный ресурс].

ГОСТ 1.1-2002.Межгосударственная система стандартизации. Термины и определения (буква У).
} 
разно регулирующих определённые виды общественных отношений [1]. Следуя этой логике под унификацией специальных упрощений можно понимать, например, установление оптимального набора таможенных упрощений, которые могут быть предоставлены юридическому лицу, соответствующему условиям присвоения статуса уполномоченного экономического оператора. Безусловно, содержание термина «унификация специальных упрощений» понятно лицам, вовлеченным в законотворческий процесс. Однако этого недостаточно, требуется его осмысление в контексте общей теории права, теории административного и таможенного права.

Исследование правоприменительной практики позволило выявить иные проблемные аспекты института УЭО. В частности, можно отметить, что существующая типовая форма соглашения таможни с уполномоченным экономическим оператором не в полной мере учитывает все практические аспекты взаимодействия УЭО и таможенного органа. Например, отсутствует состав сведений, которые должен направить УЭО в таможенный орган для информирования о планируемом прибытии транспортного средства на открытые площадки и иные территории уполномоченного экономического оператора ${ }^{5}$.

Современная практика таможенного администрирования приводит к выводу о необходимости совершенствования таможенного регулирования в связи с наличием таких проблемных вопросов как:

1) отсутствие установленных требований к порядку ведения системы учета коммерческой документации уполномоченного экономического оператора;

2) учет особого статуса УЭО при разработке мер применения системы управления рисками;

3) разработка условий, при которых УЭО может быть включен в реестр таможенных представителей и, наоборот, для возможного зачета ряда уже выполненных требований при изначальном включении в соответствующий реестр;

4) приведение формы обязательства о подаче таможенной декларации и представлении

\footnotetext{
5 Кожуховский В. Оценка проблем и перспектив развития института уполномоченного экономического оператора // Консультативный совет по работе с участниками внешнеторговой деятельности при Центральном таможенном управлении. Заседание от 20 июня 2013 г. - C.5.
}

необходимых документов и сведений в соответствие с требованиями таможенного законодательства ЕАЭС.

Подтверждение позиции о необходимости разработки новых подходов таможенного администрирования на территории ТС в части взаимного признания правового статуса УЭО таможенными органами Белоруссии, Казахстана и России нашло отражение в материалах заседания Общественноконсультативного совета Государственного таможенного комитета Республики Беларусь от 20.06.2013 г., в рамках которого таможенная служба взяла обязательство «при проведении двухсторонних встреч с представителями сопредельных таможенных администраций включать в повестку дня вопрос о паритете признания уполномоченных экономических операторов» ${ }^{6}$.

Несмотря на особенности института УЭО, несомненно существующие в странах ближнего и дальнего зарубежья, можно сделать однозначные выводы о том, что генеральная линия развития уполномоченных экономических операторов в целом едина. Необходимо подчеркнуть, что основные экономики мира рассматривают УЭО как основу упрощения таможенных процедур и, самое главное, как основу, обеспечивающую безопасность торговли как для предпринимателей, так и для государства. Таможенные службы видят в УЭО, прежде всего, партнёра по диалогу, предоставляя серьёзные упрощения взамен на гарантии соблюдения законодательства.

Институт УЭО интенсивно развивается во всём мире и требует своего скорейшего развития и в ЕАЭС. В настоящий момент вопрос совершенствования института УЭО связан с совершенствованием административноправового статуса уполномоченного экономического оператора в ЕАЭС.

Неполная реализация потенциала УЭО, зафиксированная в таможенном законодательстве ЕАЭС, лишает выгод как добропорядочных участников ВЭД, так и таможню, порождая взаимное недовольство, недоверие. Сложившаяся ситуация требует изменений правового характера. Вместе с тем, ускоряя движение в этом направлении, требуется тщательно взвешивать каждый шаг, проводить широкое обсуждение, учитывать опыт

6 П.5.3 Протокола заседания Общественноконсультативного совета Государственного таможенного комитета Республики Беларусь от 20.06.2013 г. № 2/6-совет, г. Минск. 
других стран, развивать упрощения для УЭО в увязке с совершенствованием механизмов таможенного контроля.

Резюмируя вышеизложенное, сформулируем основные направления совершенствования административно-правового статуса УЭО в ЕАЭС на современном этапе.

В этом контексте направления совершенствования правового статуса УЭО в ЕАЭС на современном этапе сводятся к следующему:

- на теоретическом и законодательном уровне необходимо дать определения терминам «таможенные упрощения», «таможенные преимущества», «специальные упрощения», «правовой статус уполномоченного экономического оператора»;

- рассмотреть возможность предоставления статуса УЭО таможенным представителям, таможенным перевозчикам, владельцам CBX и др.;

- рассмотреть вопрос о расширении перечня специальных упрощений для УЭО, связанных с упрощением таможенного контроля;

- подойти к вопросу взаимного признания правового статуса УЭО таможенными органами Белоруссии, Казахстана, России, Киргизстана и Армении;
- рассмотреть вопрос о разработке и внедрении в работу единого информационного продукта, обеспечивающего оперативное взаимодействие таможенных органов государствчленов ЕАЭС в части авторизации (предоставления статуса) УЭО, применения мер таможенного контроля, а также сотрудничество, обмен информацией таможенных органов и участников ВЭД в соответствии с требованиями ВТамО).

Выше обозначенные вопросы необходимо позиционировать в рамках разрабатываемой концепции совершенствования таможенного администрирования в Евразийском экономическом союзе. При этом в основе совершенствования института УЭО, а вместе с ним и административно-правового статуса УЭО, должны находиться стандарты Всемирной таможенной организации и передовая зарубежная правоприменительная практика таможенного регулирования. Вместе с тем, использование зарубежного опыта, новаций и результатов правоприменительной практики в рассматриваемой области таможенных правоотношений необходимо осуществлять с учетом национальной специфики таможенного регулирования [7].

\section{Лumepamypa}

1. Большая советская энциклопедия. - М.: Советская энциклопедия. 1969-1978.

2. Агамагомедова, С.А. Оптимизация таможенных операций в проекте Таможенного кодекса Евразийского экономического союза // Вестник Российской таможенной академии. 2015. № 4 (33). C. 80-86.

3. Гокинаева, И.А. Порядок использования специальных упрощений, предоставляемых уполномоченному экономическому оператору // Мир экономики и права. 2014. № 10-11. С. 40-59.

4. Дорошенко, Г.И. Экономические и информационные аспекты взаимодействия таможни и бизнеса на современном этапе // Экономика и современный менеджмент: теория и практика. 2014. № 42. С. 33-39.

5. Корняков, К.А. Новые технологии как средство модернизации таможенного контроля: монография / К.А. Корняков, Ю.Н. Егоров, А.Н. Яцушко // Российская таможенная академия. - Москва, 2014.

6. Кулешов, А.В. Организация таможенного контроля товаров и транспортных средств: учеб. пособие / А.В. Кулешов, В.А. Черных, О.В. Шишкина // - М.: РТА, 2013.

7. Некрасов, Д.В. Направления совершенствования правового статуса УЭО // Черные дыры в российском законодательстве. 2013.- № 6. - С.125-131.

8. Некрасов, Д.В. Программа уполномоченного экономического оператора как инструмент совершенствования его административно-правового статуса // Административное и муниципальное право. 2013. № 12. С. 1156-1161.

9. Петрова, И.С. К вопросу о различиях в правовом статусе уполномоченного экономического оператора в Таможенном союзе / Актуальные вопросы в научной работе и образовательной деятельности: сб. науч. тр. по материалам Международной научно-практ. конф. 2014. С. 118-119.

10. Тунтаев, Р.И. Таможенный контроль после выпуска товаров: учеб. пособие / Р.И. Тунтаев, К.В. Трубицын, Е.В. Чекушкин // - СПб.: ИЦ «Интермедия», 2015.

Галоян Акоп Давитович - студент, ФГБОУ ВО «Самарский государственный технический университет», г. Самара, e-mail: akopgaloyan@ mail.ru. 
Чекушкин Евгений Викторович - доцент, ФГБОУ ВО «Самарский государственный технический университет», г. Самара, e-mail: chek82@yandex.ru.

Трубицын Константин Викторович - кандидат экономических наук, доцент. ФГБОУ ВО «Самарский государственный технический университет», г. Самара, e-mail: tef-samgtu@ yandex.ru.

Ткачев Василий Константинович - ассистент. ФГБОУ ВО «Самарский государственный технический университет», г. Самара, e-mail: tvk93@yandex.ru.

Дата поступления 7 мая 2016 г.

DOI: 10.14529/iimj160303

\title{
THE MAIN DIRECTIONS OF IMPROVING THE ADMINISTRATIVE AND LEGAL STATUS OF AUTHORIZED ECONOMIC OPERATOR
}

\author{
A.D. GALOYAN, E.V. CHEKUSHKIN, K.V. TRUBITSYN, V.K. TKACHEV \\ Samara State Technical University, Samara, Russia
}

The article analyzes the main directions of improving the administrative and legal status of the authorized economic operator on the territory of the Russian Federation and in other countries - participants of the Eurasian Economic Union. The place of the institute of authorized economic operator in the Development Strategy of the Customs Service of the Russian Federation until 2020 is shown. The concept of the AEO in the customs legislation, taking account of the EAEC Framework security standards to simplify international trade is presented. As a part of the resolution of issues related to the implementation of the potential for AEO investigated EAEC customs legislation, particularly law enforcement customs authorities of the Member States EAEC, and the practice of customs administration abroad. The problematic issues in the absence of the necessary conceptual apparatus with the possible development of the concept of improving the administrative and legal status of the AEO are revealed. The result of the research detected some law enforcement problematic aspects of the institute of authorized economic operator. The evaluation of current practices of customs administration formulated the basic directions of improvement of administrative and legal status of AEO in EAEC at the present stage.

Keywords: authorized economic operator; the development strategy of the Customs Service of the Russian Federation until 2020; Eurasian Economic Union; Framework of Standards to Secure simplify global trade; unification of special simplifications; customs administration.

\section{References}

1. The great Soviet encyclopedia. - M.: Soviet encyclopedia. 1969-1978.

2. Agamagomedova S. A. Optimization of customs operations in the Customs code of the Eurasian economic Union // Bulletin of the Russian customs Academy. 2015. No. 4 (33). P. 80-86.

3. Gokinaev I. A. How to use special simplifications provided to authorized economic operator // World of economy and law. 2014. No. 10-11. P. 40-59.

4. Doroshenko G. I. Economic and informational aspects of interactions between customs and business at the present stage // Economics and modern management: theory and practice. 2014. No. 42. P. 33-39.

5. Kornyakov K. A. New technologies as a means of modernization of customs control: monograph / K. A. Kornyakov, Yu. N. Egorov, A. N. Yatsushko; Russian customs Academy. - Moscow, 2014.

6. Kuleshov A. V. Organization of customs control of goods and means of transport: manual / A. V. Kuleshov, V. A. Chernykh, O.V. Shishkina. - M.: RTA, 2013.

7. Nekrasov D. V. Areas of improvement of the legal status of AEO // Black holes in Russian legislation. 2013. - No. 6. - P. 125-131.

8. Nekrasov D. V. The authorized economic operator program as a tool for the improvement of his administrative legal status // Administrative and municipal law. 2013. No. 12. P. 1156-1161. 
9. Petrova I. S. To the question about the differences in the legal status of the authorized economic operator in the Customs Union / Topical issues in scientific work and educational activity: collection of scientific works. Treatise volume on the materials of International scientific-applied conference 2014. P. 118-119.

10. Tuntaev R. I. Customs control after release of goods: textbook / R. I. Tuntaev, K.V. Trubitsyn, E.V., Chekushkin. - SPb.: Its "Intermediya", 2015.

Galoyan Akop Davitovich - Student, Samara State Technical University, Samara, e-mail: akopgaloyan@mail.ru.

Chekushkin Evgeniy Viktorovich - Associate Professor, Samara State Technical University, Samara, e-mail:chek82@yandex.ru.

Trubitsyn Konstantin Viktorovich - Candidate of economic sciences, associate professor, Samara State Technical University, Samara, e-mail: tef-samgtu@yandex.ru.

Tkachev Vasiliy Konstantinovich - Assistant, Samara State Technical University, Samara, e-mail: tvk93@yandex.ru.

Received 7 May 2016

\section{ОБРАЗЕЦ ЦИТИРОВАНИЯ}

Галоян, А.Д. Основные направления совершенствования административноправового статуса уполномоченного экономического оператора. / А.Д. Галоян, К.В. Трубицын, Е.В. Чекушкин, В.К. Ткачев // Журнал Управление инвестициями и инновациями. - 2016. - № 3. С. 18 - 23. DOI:10.14529/iimj160303

\section{FOR CITATION}

Galoyan, A.D., Trubitsyn, K.V., Chekushkin E.V., Tkachev, V.K. The main directions of improving the administrative and legal status of authorized economic operator. Investment and innovation management journal. - 2016. - No.3. pp. 18 - 23. DOI: 10.14529/iimj160303 